\title{
Editorial
}

\section{Research based advocacy on current public health issues: a duty long ignored}

Community physicians have a key responsibility towards public health in the country. Most of us doctors have been trained with public money and the country expects us to deliver the duty expected from us. However, the public health hazards are mounting day by day.

From the point of view of the public, doctors look insensitive to or ignorant of these escalating public health problems. It won't be surprising if one questions whether doctors are incapable of advocating relevant sectors on important and urgent public health issues.

What the country experiences currently may not be what is traditionally called public health problems. However, so many events, which are detrimental to the health are taking place. Though it is impossible to list all of those here it is worth mentioning a few. One such problem is the increasing risk of using high ways. Incompetent drivers, poor road conditions, carelessness of pedestrians, probably due to their ignorance in highway rules, are some apparent risk factors. Whatever the reasons may be, it is necessary to identify those urgently, as deaths on roads have become a day-to-day occurrence.

Pollution of air, more dangerously indoor than outdoors caused by vehicle fumes, kitchen and cigarette smoke, and industrial gases is a serious hazard (1). Measures against air pollution are either ineffective or grossly inadequate. What is alarming is lack of quality and quantity of public health services related to environmental health. Industrial effluents are released to the environment without treating sufficiently. Public Health Inspectors are not given necessary encouragement and support by their supervisors and administrators to combat these hazards. They are often harassed by various elements in the community when they try to discharge their duties.

Violence against individuals, particularly women and children, harassments to women employed in foreign countries particularly in the Middle East are very frequent as seen in media. However, research in these areas is very scanty. Sri Lanka is highly vulnerable for HIV/AIDS. It has been observed that research gone into this disease that has caused a global pandemic is very little in our country.

Though maternal mortality is low, morbidity appears to be very high. This area needs to be addressed without delay.

This is only the tip of the iceberg. What is expected of us community physicians? We have a responsibility of advocating all the relevant sectors, from policy makers thought implementers to the general public, on how to reduce the risks to the lives of people. We can do this through the College of Community Physicians, having identified it as a priority.

It is essential to promote field research in these areas and young researchers should be encouraged to take up research in the areas relevant to the needs of the country. It is our duty to identify priority areas for research. We must also lobby for funding from local and foreign agencies and philanthropists. We can work through established research institutions like universities or by establishing research centers for this purpose. Available funds should be granted for suitable research proposals of postgraduate students. There are many other ways that we can contribute as doctors more importantly as community physicians to help bring down the risks to the lives of people. My effort by citing these few examples is to remind about an apparently forgotten responsibility of us and to reiterate the urgency for action. We are already late. We have little time before it's too late.

\section{Reference:}

1. Manouri P Senanayaka. The air we breathe: is it safe for children? Professor CC De Siva Memorial oration $5^{\text {th }}$ September 2003 BMICH, Sri Lanka

Dr. Wasantha Gunathunga

Editor,

September 2003 